(C) 2021, The Authors. Published by Elsevier Inc. and Fass Inc. on behalf of the American Dairy Science Association ${ }^{\circledR}$. This is an open access article under the CC BY-NC-ND license (http://creativecommons.org/licenses/by-nc-nd/4.0/).

\title{
Genetic analysis of semen characteristic traits in Norwegian Red bulls at the artificial insemination center
}

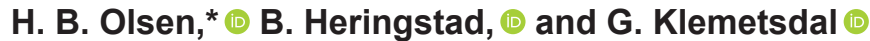 \\ Department of Animal and Aquacultural Sciences, Faculty of Biosciences, Norwegian University of Life Sciences, PO Box 5003,1433 Aas, \\ Norway
}

\begin{abstract}
Compared with cow fertility, genetic analyses of bull fertility are limited and based on relatively few animals. The aim of the present study was to estimate genetic parameters for semen characteristics of Norwegian Red bulls at the artificial insemination (AI) center (Geno AI station, Stange, Norway) and to estimate genetic correlations between some of these traits and andrology traits measured at the performance test station. The data from the AI center consisted of records from 137,919 semen collections from 3,145 bulls with information on semen weight, sperm concentration, motility before and after cryopreservation, motility change during cryopreservation, and number of accepted straws made. Data from the performance test station included 12,522 observations from 3,219 bulls on semen volume, concentration, and motility (\%) when fresh and after storing for 24 and $48 \mathrm{~h}$. Genetic parameters were estimated using linear animal repeatability models that included fixed effects of year-month of observation, age of bull, interaction between semen collection number, and interval between collections for all traits and type of diluter for postcryopreservation traits. The random effects included test-day, permanent environmental, and additive genetic effects of the bull. Based on records from the AI center, we found that semen weight, sperm concentration, and number of straws were moderately heritable $(0.18-0.20)$, whereas motility had a lower heritability (0.02-0.08). Heritability of motility (\%) was higher after cryopreservation than before. Genetic correlations among the semen characteristics ranged from unfavorable $(-0.35)$ to favorable (0.93), with standard errors ranging from 0.02 to 0.22 . Among the most precise genetic correlation estimates, number of straws made from a batch correlated favorably with semen weight $(0.62 \pm 0.06)$ and sperm concentration $(0.44 \pm 0.08)$, whereas sperm concentration was nega-
\end{abstract}

Received July 15, 2020.

Accepted January 25, 2021.

*Corresponding author: henriette.berg.olsen@nmbu.no tively correlated with weight $(-0.33 \pm 0.09)$. The genetic correlation between motility $(\%)$ before and after cryopreservation was $0.64 \pm 0.14$, and motility change during cryopreservation had a strong favorable genetic correlation with motility after cryopreservation $(-0.93$ \pm 0.02 ). The estimated genetic correlation (standard error) between the traits volume, concentration, and motility when fresh measured at the performance test station and their respective corresponding traits at the AI center were 0.83 (0.05), 0.78 (0.09), and 0.49 (0.31). The final product at the AI center (number of accepted straws) correlated genetically favorably with all semen characteristic traits recorded at the performance test station (ranging from 0.51 to 0.67 ). Our results show that the andrology testing done at the performance test station is a resource to identify the genetically best bulls for AI production.

Key words: andrology, bull fertility, genetic parameter

\section{INTRODUCTION}

Extensive research has been done to evaluate female fertility traits and to estimate their heritability (Berry et al., 2014), and cow fertility is now included in the total merit index of many dairy cattle populations (Pryce et al., 2014). Even though one bull can be used on thousands of females with frozen semen and AI, genetic studies of bull fertility have received much less attention than female fertility, and the studies performed have generally been based on relatively small data sets. Sufficient semen quality is required for the sperm cells to fertilize the egg and can thereby serve as indicator traits for field fertility, and favorable genetic correlations have been documented between semen characteristics and female reproductive performance in cattle (Johnston et al., 2014; Hagiya et al., 2018). Heritability tends to be larger for semen characteristics than for female fertility traits (Berry et al., 2014) but varies considerably both between and within traits because of differences in population and breed, maturity of the bulls, how the traits are recorded and defined, and statistical modeling and sample size. Berry et al. (2014) 
performed a meta-analysis of the most commonly used reproductive traits and found that sperm volume and concentration were moderately heritable $(0.20$ and 0.17 , respectively), whereas the heritability of motility was low (0.05). More recent studies have estimated the heritability of volume to be between 0.12 and 0.28 , the heritability of concentration to be between 0.14 and 0.27 , and the heritability of motility to be between 0.03 and 0.37 (Al-Kanaan et al., 2015; Sarakul et al., 2018; Berry et al., 2019; Olsen et al., 2020a). Heritability of motility after cryopreservation has been estimated to range between 0.13 and 0.24 (Ducrocq and Humblot, 1995; Karoui et al., 2011; Berry et al., 2019).

Similar to the heritability estimates, genetic correlations among semen characteristic traits vary between studies. The meta-analysis by Berry et al. (2014) found that greater sperm concentration was genetically associated with higher sperm motility but only weakly associated with volume, which was supported by our analysis of data for young bulls at the performance test station (Olsen et al., 2020a). Other studies have estimated the genetic correlation between sperm volume and concentration to be strongly negative (Ducrocq and Humblot, 1995; Berry et al., 2019). Further, motility after freezing and thawing has been found to be weakly or negatively genetically correlated with volume and positively correlated with concentration and to have a strongly positive genetic correlation with motility before freezing (Karoui et al., 2011; Berry et al., 2019).

Olsen et al. (2020a) found that all semen characteristic traits measured on young bulls at the test station showed a slightly unfavorable genetic trend between 1994 and 2016. Although the genetic decline raises concern, we do not know the genetic associations between these traits and semen characteristics measured on Norwegian Red (NR) bulls in semen production at the AI center. A genetic study of semen characteristics for NR AI bulls has so far not been performed. The aim of this study was therefore to estimate genetic parameters for semen characteristics of AI bulls and to estimate genetic correlations between these traits and andrology traits measured at the test station.

\section{MATERIALS AND METHODS}

\section{Data}

Data from a total of 144,095 semen collections from 3,150 NR bulls routinely collected from 1994 to January 2020 at the Geno AI station (Stange, Norway) were available. The routine for semen collection was initiated by bulls being taken to the collection area and allowed 2 false mounts to become aroused before being tied up. Ten minutes later the bulls were allowed at least 1 false mount, and semen was collected. After another $10 \mathrm{~min}$ the procedure was repeated, giving 2 ejaculates in total per semen collection (S. Reisvaag, Geno AI center, Stange, Norway; personal communication). The general rule was that the ejaculates were not mixed if more than 20 min had passed between semen collections.

To ensure optimal fertility results from semen used for insemination, Geno controls all ejaculates when fresh and after freezing and thawing. Initially, collected semen was visually inspected, and the ejaculate was discarded if abnormalities such as discoloration, blood, or visible clusters of any material were noted. The 2 ejaculates were mixed and weighed before sperm concentration was measured with a photometer. Samples with $<390 \times 10^{6}$ spermatozoa $/ \mathrm{mL}$ were discarded. The weight and sperm concentration of the sample determined the amount of diluter, and ejaculates with $<1$ $\mathrm{g}$ of semen or $<10 \mathrm{~g}$ of total weight (ejaculate + diluter) were discarded. Subjective analysis with a phase contrast microscope was used to assess percentage of motile sperm cells (mot\%pre), starting at 0 with $5 \%$ increments; progressive motility score on a scale of 1 to 4 (mot_pre); and sperm defects such as loose heads or abnormalities in the tail or intermediate part as well as proximal and distal droplets. Samples with $<70 \%$ motile sperm cells, motility score $<3,>10 \%$ of a particular sperm defect, or $>17 \%$ defects in total were discarded. After samples were cooled to $5 \pm 3^{\circ} \mathrm{C}$, diluted a second time, and properly mixed, they were ready to be filled into straws. The straws were frozen following IMV Technologies' standard freezing curve for bull semen and stored in a container with liquid nitrogen until evaluation of semen quality following cryopreservation. One straw per batch was reactivated (heated to $35 \pm$ $3^{\circ} \mathrm{C}$ ), and percent motility (mot\%post), motility score (mot_post), and percentages of sperm defects were measured in the same way as when fresh, but the acceptable threshold level for motility was lower. Now, samples with $<50 \%$ motile sperm cells, motility score $<3,>10 \%$ of a particular sperm defect, or $>17 \%$ defects in total were discarded. The change in motility during cryopreservation (mot\%change) was calculated as the difference between mot\%pre and mot\%post. If the sample was rejected before cryopreservation, it would not be measured after cryopreservation; however, this concerned few records (Table 1). If the semen collection was approved at all levels of assessment, the number of straws made from that batch was recorded (n_straw).

For genetic analyses, only records with semen weight $>0$ were kept. Observations with weight $>35$, sperm concentration $<250 \times 10^{6}$ or $>2,800 \times 10^{6}$, n_straw $<20$ or $>3,000$, or mot\%change $<0$ were considered erroneous and omitted ( $\mathrm{n}=10,575$ observations). Furthermore, records were excluded if the bull was younger 
than 13 mo or older than 100 mo at the time of collection. Age class of the bull at the time of collection was defined as age in months from 13 to 39 and thereafter grouped in intervals of 10 . The data contained a total of 284 year-month ( $\left.\mathbf{y r} \_\mathbf{m o}\right)$ classes after excluding observations from yr_mo 200504, 200505, and 200506, containing only 1 observation each. Due to few semen collections performed in July each year, recordings during this month were combined with June registrations. Semen collection number per bull was categorized as $1, \ldots, 10$ and thereafter in intervals of 10 up to $\geq 100$. Interval between semen collections varied and was defined as 0 (twice on the same day), 2 ( 1 or $2 \mathrm{~d}$ ), $3, \ldots, 7$, and $\geq 8 \mathrm{~d}$ between semen collections. Semen collection number and interval between collections were combined to a joint fixed effect (ncol_interval) with 151 levels, where, for example, 4_3 means the bull's fourth semen collection with $3 \mathrm{~d}$ since the previous collection. Because of few observations in ncol_interval $3 \_2$ and $4 \_2$, those were combined with $3 \_3$ and $4 \_3$, respectively. Type of diluter was changed during the period of data collection from milk to Biladyl (Minitube), and SpermVital (Kommisrud et al., 2008) was used for $2.7 \%$ of the ejaculates. Effect of diluter was included only when analyzing the postcryopreservation traits. Test day was included as a random effect because the number of observations per subclass was small.

After edits, the data set had a total of 137,919 observations on 3,145 NR bulls, with descriptive statistics given in Table 1. Before grouping, the mean interval between semen collection was $7 \mathrm{~d}$ and the median was 4. Bulls had on average 51 semen collections, and their mean age at day of collection was 27 mo.

Also available were andrology data from the bull breeding soundness evaluation at the performance test station, where the most promising NR bull calves were tested each year. The calves arrived at the station at 4 to 5 mo of age, and growth, conformation, and temperament were assessed during the stay. At the end of the stay, when the bulls were around 12 mo old, several andrology traits were measured and used to ensure that only bulls with acceptable semen quality were selected and sent to the AI center. The andrology data from the bull breeding soundness evaluation were analyzed in a previous study (Olsen et al., 2020a), and we used 12,522 observations on 3,219 bulls measured from 1994 to 2016. Here, sperm quantity (referred to here as "volume") was measured (in $\mathrm{mL}$ ) directly from the measurement cup, and concentration was recorded by a photometer. The photometer was replaced in March 2013; up until this date, the photometer used could not measure concentrations $<390 \times 10^{6}$ spermatozoa/ $\mathrm{mL}$, and concentration was set to $390 \times 10^{6}$ if the photometer showed a value of 0 but sperm cells were found during microscope evaluation. Consequently, concentration was defined as 2 traits, before (conc1) and after (conc2) March 2013; conc2 was as recorded with the higher-resolution photometer, and conc1 was categorized into 10 classes $(0,1-390$, then in intervals of 200 , and finally $>1,790 \times 10^{6}$ spermatozoa $/ \mathrm{mL}$ ). Motility was measured subjectively under a phase contrast microscope at 3 time points: when fresh and after storing for 24 and $48 \mathrm{~h}$. Only semen collections with volume $>0 \mathrm{~mL}$ were kept for analyses. Samples with volume $>12 \mathrm{~mL}$ or sperm concentration $>3,000$ $\times 10^{6}$ spermatozoa $/ \mathrm{mL}$ were considered erroneous and removed. Bulls had to be between 10.5 and 15.5 mo old at the test day, and only bulls that had been assigned a group number and group year (the group and the year bulls were transferred from the station) were kept. Similar to the data from the AI station, we included an interaction between semen collection number $(1=$ first semen collection to $6=$ sixth or later collection) and number of days since previous collection $(1=1-4 \mathrm{~d}, 2$ $=5-10 \mathrm{~d}$, and $3=>10 \mathrm{~d}$ ) as a fixed effect in addition to group-year and age of the bulls in months. See Olsen et al. (2020a) for further details on semen collection, editing of data, and descriptive statistics.

Table 1. Descriptive statistics of Norwegian Red bulls from the Geno AI station (Stange, Norway)

\begin{tabular}{lrrrrrr}
\hline Trait & Records, \\
no & $\begin{array}{c}\text { Bulls, } \\
\text { no }\end{array}$ & Mean & SD & Minimum & Maximum \\
\hline weight & 137,772 & 3,143 & 8.67 & 3.10 & 0.1 & 35 \\
conc & 136,470 & 3,134 & $1,184.29$ & 378.83 & 250 & 2,800 \\
mot_pre & 135,064 & 3,134 & 3.97 & 0.18 & 1 & 4 \\
mot\%pre & 85,368 & 3,107 & 77.96 & 4.97 & 0 & 90 \\
mot_post & 135,811 & 3,133 & 3.94 & 0.27 & 1 & 4 \\
mot\%post & 133,460 & 3,123 & 55.26 & 6.12 & 0 & 80 \\
mot\%change & 84,246 & 3,104 & 23.15 & 7.11 & 0 & 85 \\
n_straw & 128,251 & 3,110 & 590.3 & 263.7 & 20 & 2,967
\end{tabular}

${ }^{1}$ weight $=$ semen weight $(\mathrm{g}) ;$ conc $=$ sperm concentration $\left(10^{6}\right.$ spermatozoa $\left./ \mathrm{mL}\right) ;$ mot_pre $=$ motility score $(1$ to 4) before cryopreservation; $\operatorname{mot} \%$ pre $=$ percentage motility before cryopreservation; mot_post $=$ motility score (1 to 4) after cryopreservation; mot\%post = percentage motility after cryopreservation; mot $\%$ change = motility change during cryopreservation; n_straw = number of accepted straws. 


\section{Models}

To estimate variance components for the traits recorded at the AI center we used univariate, linear animal repeatability models in DMU (Madsen and Jensen, 2013). The following model was defined:

$$
\begin{gathered}
\mathrm{Y}_{i j k l m n o}=\mu+\text { age }_{i}+\mathrm{yr} \_\mathrm{mo}_{j}+\text { ncol_interval } \\
\\
+ \text { diluter }_{l}+\text { testday }_{m}+\mathrm{a}_{n}+\mathrm{pe}_{n}+\mathrm{e}_{i j k l m n o},
\end{gathered}
$$

where $\mathrm{Y}_{i j k l m n o}$ is the oth observation on one of the semen characteristics; $\mu$ is the mean; age $_{i}$ is the fixed effect of the $i$ th age class in month $i=13, \ldots, 39$, thereafter in intervals of 10 up to 100 (33 classes); yr_mo $_{j}$ is the fixed effect of the $j$ th month and year, $j=1, \ldots, 284$; ncol_interval ${ }_{k}$ is the fixed effect of the $k$ th group of semen collection number and interval between collections, $k=1, \ldots, 151$; diluter ${ }_{l}$ is the fixed effect of the $l$ th diluter, $l=$ milk, Biladyl, or SpermVital (included only for the postcryopreservation traits); testday $_{m}$ is the random effect of the $m$ th test day $\sim N\left(0, \mathbf{I} \sigma_{\mathrm{td}}^{2}\right)$, where $\mathbf{I}$ is an identity matrix and $\sigma_{\mathrm{td}}^{2}$ is the test-day variance; $\mathrm{a}_{n}$ is the random genetic effect of the $n$th bull $\sim N\left(0, \mathbf{A} \sigma_{\mathrm{a}}^{2}\right)$, with $\sigma_{\mathrm{a}}^{2}$ being the additive genetic variance; $\mathrm{pe}_{n}$ is the random permanent environment effect of the bull $\sim N\left(0, \mathbf{I} \sigma_{\mathrm{pe}}^{2}\right)$, with $\sigma_{\mathrm{pe}}^{2}$ being the permanent environmental variance; and $\mathrm{e}_{i j k l m n o}$ is the random residual $\sim N\left(0, \mathbf{I} \sigma_{\mathrm{e}}^{2}\right)$, with $\sigma_{\mathrm{e}}^{2}$ being the residual variance. The pedigree of the bulls was traced back as far as possible, up to 8 generations, and the additive genetic relationship matrix A included 32,078 animals.

Bivariate linear animal models were used to estimate genetic correlations among the semen characteristics recorded at the AI center and with the traits recorded at the performance test station. The effects included in the model used for the AI traits were as described above, whereas the following model was used for the traits recorded at the performance test station:

$$
\begin{gathered}
\mathrm{Y}_{i j k l m o}=\mu+\text { age }_{i}+\text { group-year }_{j} \\
+ \text { collection_n-interval }_{k}+\text { testday }_{l}+\mathrm{a}_{m} \\
+\mathrm{pe}_{m}+\mathrm{e}_{i j k l m o},
\end{gathered}
$$

where $\mathrm{Y}_{i j k l m o}$ is the oth observation on one of the 6 andrology traits; $\mu$ is the mean; age $_{i}$ is the fixed effect of the $i$ th age in months, $i=11, \ldots, 15$;roup-year $_{j}$ is the fixed effect of the $j$ th group and year the bull left the test station, $j=1, \ldots, 131$; collection_n-interval ${ }_{k}$ is the fixed effect of the $k$ th group of ejaculate number
$(1=$ first semen collection to $6=$ sixth or more collection) and interval in days since previous collection (1 $=1-4 \mathrm{~d}, 2=5-10 \mathrm{~d}$, and $3=>10 \mathrm{~d}), k=1, \ldots, 16$; testday $_{l}$ is the random effect of the lth test day; $\mathrm{a}_{m}$ is the random genetic effect of the $m$ th bull; $\mathrm{pe}_{m}$ is the random permanent environment effect of the bull; and $\mathrm{e}_{i j k l m o}$ is the random residual.

The following assumptions were made for the distribution of the random test day (td), permanent environmental (pe), additive genetic (a), and residual (e) effects included in the models, where the subscript numbers refer to location $(1=\mathrm{AI}$ center and $2=\mathrm{AI}$ center or test station):

$$
\begin{gathered}
{\left[\begin{array}{l}
\mathbf{t d}_{1} \\
\mathbf{t d}_{2}
\end{array}\right] \sim N\left[\left(\begin{array}{l}
0 \\
0
\end{array}\right), \mathbf{I} \otimes\left(\begin{array}{cc}
\sigma_{\mathrm{td}_{1}}^{2} & \sigma_{\mathrm{td}_{1} \mathrm{td}_{2}} \\
\sigma_{\mathrm{td}_{1} \mathrm{td}_{2}} & \sigma_{\mathrm{td}_{2}}^{2}
\end{array}\right)\right],} \\
{\left[\begin{array}{l}
\mathbf{p e}_{1} \\
\mathbf{p e}_{2}
\end{array}\right] \sim N\left[\left(\begin{array}{l}
0 \\
0
\end{array}\right), \mathbf{I} \otimes\left(\begin{array}{cc}
\sigma_{\mathrm{pe}_{1}}^{2} & \sigma_{\mathrm{pe}_{1} \mathrm{pe}_{2}} \\
\sigma_{\mathrm{pe}_{1} \mathrm{pe}_{2}} & \sigma_{\mathrm{pe}_{2}}^{2}
\end{array}\right)\right],} \\
{\left[\begin{array}{l}
\mathbf{a}_{1} \\
\mathbf{a}_{2}
\end{array}\right] \sim N\left[\left(\begin{array}{l}
0 \\
0
\end{array}\right), \mathbf{A} \otimes\left(\begin{array}{cc}
\sigma_{\mathrm{a}_{1}}^{2} & \sigma_{\mathrm{a}_{1} \mathrm{a}_{2}} \\
\sigma_{\mathrm{a}_{1} \mathrm{a}_{2}} & \sigma_{\mathrm{a}_{2}}^{2}
\end{array}\right)\right],} \\
{\left[\begin{array}{l}
\mathbf{e}_{1} \\
\mathbf{e}_{2}
\end{array}\right] \sim N\left[\left(\begin{array}{cc}
\sigma_{\mathrm{e}_{1}}^{2} & \sigma_{\mathrm{e}_{1} \mathrm{e}_{2}} \\
0
\end{array}\right), \quad \mathbf{I} \otimes\left[\begin{array}{cc}
\sigma_{\mathrm{e}_{1} \mathrm{e}_{2}} & \sigma_{\mathrm{e}_{2}}^{2}
\end{array}\right)\right]}
\end{gathered}
$$

where $\mathbf{I}$ is an identity matrix and $\mathbf{A}$ is the additive genetic relationship matrix, including 32,078 animals if location for trait 2 was the AI center and 46,635 animals if trait 2 was from the test station. The covariance matrices show variances on the diagonal and covariances on the off-diagonal. For analyses of one trait recorded at the AI center and the other recorded at the performance test station, the residual covariances, $\sigma_{\mathrm{e}_{1} \mathrm{e}_{2}}$, were set to 0 because the measurements differed in time and place.

The heritability $\left(\mathrm{h}^{2}\right)$ and repeatability $\left(\mathrm{c}^{2}\right)$ were calculated using the following formulas, where variables are as defined previously:

$$
\begin{aligned}
& \mathrm{h}^{2}=\frac{\sigma_{\mathrm{a}}^{2}}{\sigma_{\mathrm{td}}^{2}+\sigma_{\mathrm{a}}^{2}+\sigma_{\mathrm{pe}}^{2}+\sigma_{\mathrm{e}}^{2}}, \\
& \mathrm{c}^{2}=\frac{\sigma_{\mathrm{a}}^{2}+\sigma_{\mathrm{pe}}^{2}}{\sigma_{\mathrm{td}}^{2}+\sigma_{\mathrm{a}}^{2}+\sigma_{\mathrm{pe}}^{2}+\sigma_{\mathrm{e}}^{2}} .
\end{aligned}
$$




\section{RESULTS AND DISCUSSION}

\section{Fixed Effects: Al Center}

Figure 1 shows the effect of the bull's age on semen weight, sperm concentration, motility change during cryopreservation, and number of straws made from one semen collection. The effect of age on various semen characteristics has been explored in many studies, and similar to our results for semen weight, findings generally show increased semen volume with increasing age (Karoui et al., 2011; Al-Kanaan et al., 2015; Berry et al., 2019). Also consistent with our results, Karoui et al. (2011) and Berry et al. (2019) observed the most rapid increase in semen volume before $2 \mathrm{yr}$ of age, and from the age of 50 mo onward the amount of semen did not change much (Figure 1). The age effect for $n \_s t r a w$ generally followed the same pattern, indicating that the number of straws strongly depended on semen weight. Similar to Berry et al. (2019), we found that semen concentration increased rapidly until 20 mo of age, reaching a maximum around 30 mo and decreasing thereafter. From 60 mo onward, concentration seems to have plateaued for the bulls in our data. Bulls from 20 to $30 \mathrm{mo}$ of age had numerically the smallest change in motility during cryopreservation, but the difference between the most extreme solutions was small and stan- dard errors were large and overlapping. Solutions for the effect of ncol_interval (results not shown) revealed that the bull's first semen collection generally had higher weight and lower sperm concentration, whereas later semen collections did not differ much in terms of amount or quality. Regarding interval between collections, both semen weight and n_straw increased with longer interval. Increasing semen volume with a longer interval between collections has been well documented in other studies; Mathevon et al. (1998), Fuerst-Waltl et al. (2006), and Al-Kanaan et al. (2015) all reported the highest volume with the longest interval between collections. Consecutive semen collections on the same day had a negative effect on change in motility during cryopreservation, and a longer interval in days gave a smaller loss in motility, but standard errors were large. The fixed effects for yr_mo (results not shown) indicated strong fluctuations over the years and variation between seasons for semen characteristics traits.

\section{Variance Components and Parameters: Al Center}

Studies considering bull fertility have typically been based on relatively few animals. Among the most recent studies, for example, Al-Kanaan et al. (2015) considered 562 bulls, Sarakul et al. (2018) included 131 bulls, and Berry et al. (2019) estimated genetic parameters based
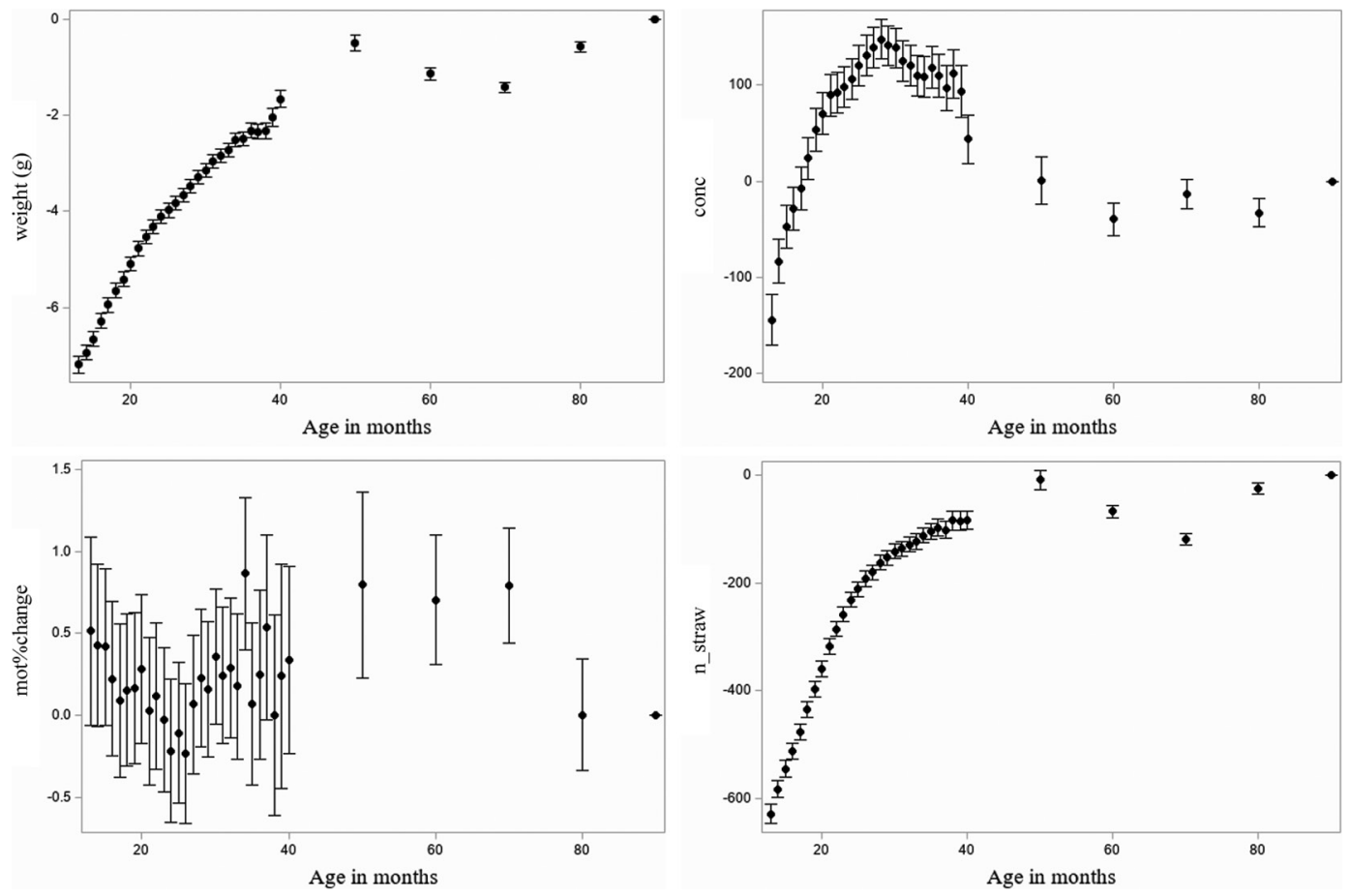

Figure 1. Solutions for fixed effect of age in months estimated with univariate models for semen weight (weight), sperm concentration (conc), motility change during cryopreservation (mot\%change), and number of straws (n_straw) made from the semen collected at the AI center of Norwegian Red bulls (Geno AI station, Stange, Norway). Age classes $>40$ mo are merged in groups of 10 . Error bars show \pm 1 SE. 
Table 2. Estimated variance components, heritability $\left(\mathrm{h}^{2}\right)$, and repeatability $\left(\mathrm{c}^{2}\right)$ (SE in parentheses) of Norwegian Red bulls from the Geno AI station (Stange, Norway)

\begin{tabular}{|c|c|c|c|c|c|c|}
\hline \multirow[b]{2}{*}{ Trait $^{1}$} & \multicolumn{4}{|c|}{ Variance component $^{2}$} & \multirow[b]{2}{*}{$h^{2}$} & \multirow[b]{2}{*}{$c^{2}$} \\
\hline & $\sigma_{\mathrm{a}}^{2}$ & $\sigma_{\mathrm{pe}}^{2}$ & $\sigma_{\mathrm{td}}^{2}$ & $\sigma_{\mathrm{e}}^{2}$ & & \\
\hline conc & $32,132(4,890)$ & $51,614(3,880)$ & $4,372(171)$ & $71,629(282)$ & $0.20(0.029)$ & $0.52(0.008)$ \\
\hline mot_pre & $0.0011(0.0003)$ & $0.0053(0.0003)$ & $0.0022(0.0001)$ & $0.0255(0.0001)$ & $0.03(0.009)$ & $0.19(0.006)$ \\
\hline $\operatorname{mot} \%$ pre & $0.40(0.16)$ & $3.22(0.19)$ & $1.52(0.07)$ & $19.15(0.10)$ & $0.02(0.006)$ & $0.15(0.005)$ \\
\hline mot_post & $0.0012(0.0004)$ & $0.0058(0.0004)$ & $0.0054(0.0002)$ & $0.0526(0.0002)$ & $0.02(0.006)$ & $0.11(0.004)$ \\
\hline n_straw & $11,021(1,494)$ & $13,902(1,155)$ & $3,221(118)$ & $32,482(133)$ & $0.18(0.022)$ & $0.41(0.008)$ \\
\hline
\end{tabular}

${ }^{1}$ weight $=$ semen weight $(\mathrm{g}) ;$ conc $=$ sperm concentration $\left(10^{6}\right.$ spermatozoa $\left./ \mathrm{mL}\right) ;$ mot_pre $=$ motility score $(1$ to 4$)$ before cryopreservation; mot $\%$ pre $=$ percentage motility before cryopreservation; mot_post $=$ motility score (1 to 4$)$ after cryopreservation; mot $\%$ post $=$ percentage motility after cryopreservation; mot\%change $=$ motility change during cryopreservation; $\mathrm{n} \_$straw $=$number of accepted straws.

${ }^{2}$ Additive genetic $\left(\sigma_{\mathrm{a}}^{2}\right)$, permanent environmental $\left(\sigma_{\mathrm{pe}}^{2}\right)$, test day $\left(\sigma_{\mathrm{td}}^{2}\right)$, and residual $\left(\sigma_{\mathrm{e}}^{2}\right)$ variance components were obtained from univariate models, but bivariate models gave very similar estimates.

on 787 bulls from 16 breeds. More than 3,000 bulls in our study permitted precise heritability estimates and genetic correlations.

Estimated variance components for the semen production traits are given in Table 2. The genetic coefficient of variation was largest for n_straw (18\%), followed by sperm concentration (15\%) and semen weight (14\%). Among the motility traits, mot\%change varied genetically the most $(6.4 \%)$, followed by mot\%post (3\%), whereas mot\%pre had the lowest genetic coefficient of variation $(0.8 \%)$. Semen weight, sperm concentration, and number of straws were moderately heritable $(0.18-0.22)$, whereas among the motility traits mot\%post had the highest heritability (0.08). The heritability estimates of semen weight $(0.22$ $\pm 0.024)$, sperm concentration $(0.20 \pm 0.029)$, and mot_pre $(0.03 \pm 0.009)$ agreed with the meta-analysis performed by Berry et al. (2014) in which heritability of volume, concentration, and motility was estimated to be $0.20,0.17$, and 0.054 , respectively. Some studies obtained considerably higher heritability estimates for motility before cryopreservation, such as 0.22 in Kealey et al. (2006) and 0.37 in Berry et al. (2019). In addition to the traits previously discussed, Berry et al. (2019) estimated genetic parameters for postcryopreservation traits. They obtained a heritability estimate for motility score after cryopreservation of 0.13 , which was larger than our estimates for mot_post of 0.02 and mot\%post of 0.08 (Table 2). Ducrocq and Humblot (1995) and Karoui et al. (2011) estimated even higher heritability for this trait (0.24 and 0.22 , respectively). Similar to Karoui et al. (2011), we found the largest heritability of motility after cryopreservation, whereas Berry et al. (2019) found the largest heritability estimate before cryopreservation, and Ducrocq and Humblot (1995) es- timated similar heritability estimates for motility score before and after cryopreservation. Regarding motility change during cryopreservation, Berry et al. (2019) obtained a heritability of 0.21 for this trait, which is considerably higher than our heritability estimate of 0.05 .

In our previous study of 3,972 bulls at the NR performance test station (Olsen et al., 2020a), the heritability for both volume and concentration was 0.14 , which is lower than the estimates in the present study. The heritability of motility in fresh samples, however, was the same based on date from the performance test station and from the AI center (0.03), but the genetic coefficient of variation was considerably lower for the adult bulls (0.8 vs. $5.3 \%)$, as was the phenotypic coefficient of variation ( 6.3 vs. $31.1 \%$ ).

One problem with estimating variance components on semen characteristics from the AI station is the potential bias arising from preselection of these traits after the performance test station. We calculated the selection intensity for the performance test station traits volume, concentration, and motility in fresh samples and after storing for 24 and $48 \mathrm{~h}$ (measured from 1994 to 2016) and found that the selection on these traits has been almost nonexistent (ranging from 0.036 for volume to 0.10 for concentration).

The repeatability (Table 2) was highest for concentration (0.52), followed by semen weight $(0.42)$ and n_straw (0.41). The repeatability for the motility traits ranged from 0.11 to 0.25 . The repeatability of semen weight and concentration were higher for bulls in AI production than for the test bulls (Olsen et al., 2020a). The increase in both heritability and repeatability is likely a result of increased age and sexual maturity resulting in more consistent semen collections. 
Table 3. Estimated genetic correlation (SE in parentheses) among semen characteristics of Norwegian Red bulls from the Geno AI station (Stange, Norway)

\begin{tabular}{|c|c|c|c|c|c|c|c|}
\hline Trait $^{1}$ & conc & mot_pre & mot\%pre & mot_post & mot\%post & mot\%change & n_straw \\
\hline conc & & $-0.06(0.15)$ & $-0.35(0.18)$ & $-0.33(0.14)$ & $-0.22(0.12)$ & $0.13(0.13)$ & $0.44(0.08)$ \\
\hline mot\%pre & & & & $0.39(0.22)$ & $0.64(0.14)$ & $-0.34(0.21)$ & $-0.05(0.18)$ \\
\hline mot_post & & & & & $0.74(0.11)$ & $-0.68(0.13)$ & $-0.20(0.15)$ \\
\hline mot\%post & & & & & & $-0.93(0.02)$ & $-0.05(0.12)$ \\
\hline mot\%change & & & & & & & $0.12(0.13)$ \\
\hline
\end{tabular}

${ }^{1}$ weight $=$ semen weight $(\mathrm{g}) ;$ conc $=$ sperm concentration $\left(10^{6}\right.$ spermatozoa $\left./ \mathrm{mL}\right) ;$ mot_pre $=$ motility score $(1$ to 4$)$ before cryopreservation; mot $\%$ pre $=$ percentage motility before cryopreservation; mot_post $=$ motility score (1 to 4$)$ after cryopreservation; mot\%post $=$ percentage motility after cryopreservation; mot\%change = motility change during cryopreservation; $\mathrm{n} \_$straw $=$number of accepted straws.

\section{Genetic Correlations: Al Center}

Estimated genetic correlations among the semen characteristic traits measured at the AI station are given in Table 3 and ranged from being unfavorable $(-0.35)$ to strongly favorable (0.96). Some of the estimates had large standard errors (ranging from 0.02 to 0.21 ), and in the following we focus on the most precise. Both semen weight and sperm concentration had favorable genetic correlation with $\mathrm{n} \_$straw (0.62 and 0.44, respectively), which is not surprising because concentration and particularly semen weight determine the number of straws that can be made from a sample. We estimated a negative genetic correlation between sperm concentration and semen weight $(-0.33 \pm 0.09)$. Berry et al. (2014) and Karoui et al. (2011) also reported a negative genetic correlation between semen weight and concentration, but their estimates were borderline significant or not significant, whereas Berry et al. (2019) obtained an estimate of $-0.40 \pm 0.20$ which agrees with the results in the present study. Furthermore, Karoui et al. (2011), Berry et al. (2014), and Berry et al. (2019) obtained positive genetic correlations between sperm concentration and motility in fresh samples of 0.73 , 0.61 , and 0.29 , respectively, whereas our corresponding estimate was negative but with a high standard error $(-0.35 \pm 0.18)$. Consistently, the same negative genetic correlations were estimated between sperm concentration and motility after cryopreservation $(-0.33$ \pm 0.14 for mot_post and $-0.22 \pm 0.12$ for mot\%post). When measured on the same scale, motility before cryopreservation correlated favorably with motility after cryopreservation $(0.59 \pm 0.15$ for motility score and $0.64 \pm 0.14$ for percentage motility). These correlation estimates were weaker than in other studies, where estimates ranged from 0.81 to 0.92 (Ducrocq and Humblot, 1995; Karoui et al., 2011; Berry et al., 2019). Furthermore, the estimated genetic correlation between the 2 measures of motility (mot_pre vs. mot\%pre and mot_post vs. mot\%post) were positive both before and after cryopreservation (0.48 and 0.74 , respectively).
Motility change during cryopreservation showed strong favorable genetic correlations with mot\%post $(-0.93 \pm$ $0.02)$ and mot_post $(-0.68 \pm 0.13)$. In contrast, Berry et al. (2019) estimated a genetic correlation of -0.19 between motility change and motility after cryopreservation.

The estimated permanent environmental correlations (Supplemental Table S1, https://figshare .com/articles/online_resource/supplementary_tables _JDS19294_docx/14627529; Olsen, 2021) and test-day correlations (Supplemental Table S2, https://figshare .com/articles/online_resource/supplementary_tables _JDS19294_docx/14627529; Olsen, 2021) are given in supplementary tables. Overall, these correlations had low standard errors.

\section{Genetic Correlations Between Traits Measured at the Al Center and Performance Test Station}

Table 4 shows the number of bulls with registrations from both the performance test station and the AI center for all trait combinations. The estimated genetic correlations between these traits can be found in Table 5. A strong, favorable genetic correlation was estimated between semen volume measured at the test station and semen weight recorded at the AI center $(0.83 \pm 0.05)$. Similarly, sperm concentrations measured at the test station and in the AI center were strongly genetically correlated $(0.78 \pm 0.09$ and $0.59 \pm 0.20$ for conc 1 and conc2, respectively). Note that conc1 was categorized into 10 categories. Table 4 shows that only 377 bulls were assessed for both conc 2 and concentration at the AI center, but the standard error was still reasonably small, likely due to the traits being recorded similarly. We estimated a favorable genetic correlation between motility in fresh samples measured at the test station and mot\%pre $(0.49 \pm 0.31)$; that is, with a high standard error. The variable motility after storing for 24 h correlated genetically favorably with both mot\%pre and mot\%post $(0.59 \pm 0.23$ and $0.58 \pm 0.15$, respec- 
Table 4. Number of bulls with data for the trait combinations of semen characteristics measured at the performance test station ${ }^{1}$ and traits measured at the Geno AI station (Stange, Norway) ${ }^{2}$ of Norwegian Red bulls

\begin{tabular}{lrrrrrrr}
\hline Trait & weight & conc & mot_pre & mot\%pre & mot_post & mot\%post & mot\%change \\
\hline volume & 2,311 & 2,303 & 2,303 & 2,280 & 2,303 & 2,297 & 2,297 \\
conc1 & 1,935 & 1,930 & 1,931 & 1,908 & 1,930 & 1,924 & 1,907 \\
conc2 & 380 & 377 & 376 & 376 & 377 & 377 & 376 \\
mot0h & 2,309 & 2,301 & 2,301 & 2,278 & 2,301 & 2,295 & 2,917 \\
mot24h & 1,989 & 1,982 & 1,982 & 1,973 & 1,982 & 1,980 & 376 \\
mot48h & 1,385 & 1,383 & 1,383 & 1,377 & 1,384 & 1,382 & 1,972 \\
\hline
\end{tabular}

${ }^{1}$ volume $=$ semen volume $(\mathrm{mL})$; conc1 $=$ sperm concentration recorded before March 2013 and categorized into 10 classes $(0,1-390$, then increments of 200, and finally $>1,790 \times 10^{6}$ spermatozoa $/ \mathrm{mL}$ ); conc2 $=$ sperm concentration recorded after March 2013 (given as $10^{6}$ spermatozoa/ $\mathrm{mL}$ ); mot0h, mot $24 \mathrm{~h}$, and mot $48 \mathrm{~h}=$ percentage motility in fresh samples and after storing for 24 and $48 \mathrm{~h}$, respectively.

${ }^{2}$ weight $=$ semen weight $(\mathrm{g}) ;$ conc $=$ sperm concentration $\left(10^{6}\right.$ spermatozoa $\left./ \mathrm{mL}\right) ;$ mot_pre $=$ motility score $(1$ to 4$)$ before cryopreservation; mot\%pre $=$ percentage motility before cryopreservation; mot_post $=$ motility score (1 to 4 ) after cryopreservation; mot $\%$ post $=$ percentage motility after cryopreservation; mot\%change $=$ motility change during cryopreservation; $\mathrm{n} \_$straw $=$number of accepted straws.

tively). However, results involving motility after storing for 24 and $48 \mathrm{~h}$ should be interpreted with caution because our previous work has indicated a selection bias for these variables, with more bulls with high-quality semen having their motility inspected after storing (Olsen et al., 2020a,b). Finally, except for conc2, all test station traits explored in this study were found to have high genetic correlations to n_straw at the AI center, with estimated genetic correlations ranging from 0.51 \pm 0.13 to $0.67 \pm 0.16$.

\section{Overall Discussion}

With a large data set consisting of 137,919 records on 3,143 bulls, and close to zero preselection for the semen traits after the performance test, genetic parameters for semen characteristics could be estimated with good precision. The heritability estimates for both semen weight and sperm concentration were somewhat larger than those found for corresponding traits at the performance test, whereas the heritability estimated for all motility traits was low in size. The low heritability estimates for motility traits may be a result of imprecise recording. The large standard errors found for the genetic correlations involving motility variables suggest the same. Thus, there is a need to reconsider the definition of the traits recorded. Sperm motility should ideally be measured objectively (e.g., with computerassisted sperm analysis). In addition to $\mathrm{n} \_$straw being a product of semen weight and sperm concentration, the trait also includes a quality aspect as only semen collections with minimum motility and normal sperm cells

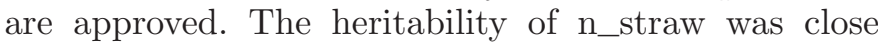
to that of semen weight and concentration, and with positive genetic correlations with both traits it could be an interesting alternative to explore. Under genomic selection, bulls are becoming younger than the average AI bulls in this study and therefore more comparable with the bulls at the performance test station. At this age, all the semen traits have been estimated with favorable genetic correlations (Olsen et al., 2020a), likely because the traits then are affected by early maturity. Still, high genetic correlations were estimated between corresponding traits in the 2 environments.

Table 5. Genetic correlations (SE in parentheses) between traits measured at the performance test station ${ }^{1}$ and traits measured at the Geno AI station (Stange, Norway) ${ }^{2}$ of Norwegian Red bulls

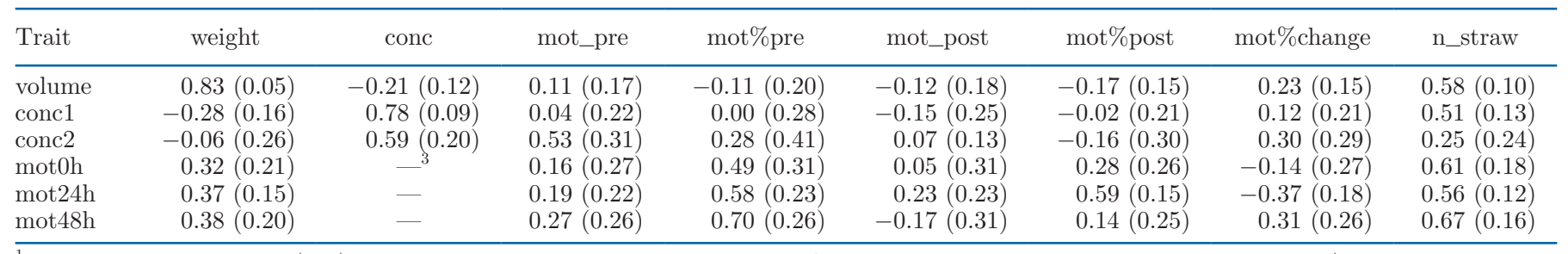

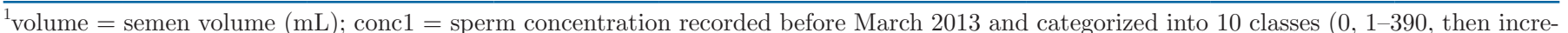
ments of 200 , and finally $>1,790 \times 10^{6}$ spermatozoa $/ \mathrm{mL}$ ); conc2 $=$ sperm concentration recorded after March 2013 (given as $10^{6}$ spermatozoa/ $\mathrm{mL}$ ); mot0h, mot24h, and mot $48 \mathrm{~h}=$ percentage motility in fresh samples and after storing for 24 and $48 \mathrm{~h}$, respectively.

${ }^{2}$ weight $=$ semen weight $(\mathrm{g})$; conc $=$ sperm concentration $\left(10^{6}\right.$ spermatozoa $\left./ \mathrm{mL}\right)$; mot_pre $=$ motility score $(1$ to 4$)$ before cryopreservation; mot $\%$ pre $=$ percentage motility before cryopreservation; mot_post $=$ motility score (1 to 4$)$ after cryopreservation; mot $\%$ post $=$ percentage motility after cryopreservation; mot\%change = motility change during cryopreservation; $\mathrm{n} \_$straw $=$number of accepted straws.

${ }^{3}$ Analysis did not converge. 


\section{CONCLUSIONS}

With a large data set, including more than 3,000 bulls, genetic parameters for semen characteristics could be estimated with good precision. Semen characteristic traits are heritable and can be used in genetic evaluation of NR bulls. Andrology traits measured at the test station were highly correlated with corresponding traits measured at the AI center, and a future genetic evaluation could preferably be based on data from both. The most promising traits to consider would be volume, concentration, motility after freezing, and number of accepted straws. The first 2 traits ensure more sperm cells per collection, motility after freezing ensures frozen semen with good quality, and number of straws is the final product of the AI center.

\section{ACKNOWLEDGMENTS}

We thank Geno (Hamar, Norway) for access to data and to The Research Council of Norway (Oslo) for funding (project no. NFR-255097/E50). We especially thank Simon Reisvaag, Ragnhild Gjeset, and Sigbjørn Karlsen at the Geno AI center for all of their help and support. The authors have not stated any conflicts of interest.

\section{REFERENCES}

Al-Kanaan, A., S. König, and K. Brügemann. 2015. Effects of heat stress on semen characteristics of Holstein bulls estimated on a continuous phenotypic and genetic scale. Livest. Sci. 177:15-24. https://doi.org/10.1016/j.livsci.2015.04.003.

Berry, D. P., B. Eivers, G. Dunne, and S. McParland. 2019. Genetics of bull semen characteristics in a multi-breed cattle population. Theriogenology 123:202-208. https://doi.org/10.1016/j.theriogenology .2018.10.006.

Berry, D. P., E. Wall, and J. E. Pryce. 2014. Genetics and genomics of reproductive performance in dairy and beef cattle. Animal 8:105-121. https://doi.org/10.1017/S1751731114000743.

Ducrocq, V., and P. Humblot. 1995. Genetic characteristics and evolution of semen production of young Normande bulls. Livest. Prod. Sci. 41:1-10. https://doi.org/10.1016/0301-6226(94)00029-7.

Fuerst-Waltl, B., H. Schwarzenbacher, C. Perner, and J. Sölkner. 2006. Effects of age and environmental factors on semen production and semen quality of Austrian Simmental bulls. Anim. Reprod. Sci. 95:27-37. https://doi.org/10.1016/j.anireprosci.2005.09.002.

Hagiya, K., T. Hanamure, H. Hayakawa, H. Abe, T. Baba, Y. Muranishi, and Y. Terawaki. 2018. Genetic correlations between yield traits or days open measured in cows and semen production traits measured in bulls. Animal 12:2027-2031. https://doi.org/10.1017/ S1751731117003470.

Johnston, D. J., N. J. Corbet, S. A. Barwick, M. L. Wolcott, and R. G. Holroyd. 2014. Genetic correlations of young bull reproductive traits and heifer puberty traits with female reproductive performance in two tropical beef genotypes in northern Australia. Anim. Prod. Sci. 54:74-84. https://doi.org/10.1071/AN13044.

Karoui, S., C. Díaz, M. Serrano, R. Cue, I. Celorrio, and M. J. Carabaño. 2011. Time trends, environmental factors and genetic basis of semen traits collected in Holstein bulls under commercial conditions. Anim. Reprod. Sci. 124:28-38. https://doi.org/10.1016/j .anireprosci.2011.02.008.

Kealey, C. G., M. D. Macneil, M. W. Tess, T. W. Geary, and R. A. Bellows. 2006. Genetic parameter estimates for scrotal circumference and semen characteristics of Line 1 Hereford bulls. J. Anim. Sci. 84:283-290.

Kommisrud, E., P. O. Hofmo, and G. Klinkenberg. 2008. Preservation and controlled delivery/release of spermatoza. WIPO, World Intellectual Property Organization, Patentscope; 2008. European Patent No. EP2048943B1/US patent No. 8,178,130 B2.

Madsen, P., and J. Jensen. 2013. A User's Guide to DMU. A Package for Analysing Multivariate Mixed Models. Version 6, release 5.2. Aarhus University.

Mathevon, M., M. M. Buhr, and J. C. M. Dekkers. 1998. Environmental, management, and genetic factors affecting semen production in Holstein bulls. J. Dairy Sci. 81:3321-3330. https://doi.org/10 .3168/jds.S0022-0302(98)75898-9.

Olsen, H. 2021. Supplementary tables JDS19294.docx. Figshare. Online resource. https://doi.org/https://doi.org/10.6084/m9.figshare 14627529.v1.

Olsen, H. B., B. Heringstad, and G. Klemetsdal. 2020a. Genetic analysis of semen characteristic traits in young Norwegian Red bulls. J. Dairy Sci. 103:545-555. https://doi.org/10.3168/jds.2019-17291.

Olsen, H. B., B. Heringstad, and G. Klemetsdal. 2020b. Genetic correlations between body weight, daily weight gain, and semen characteristic traits in young Norwegian Red bulls. J. Dairy Sci. 103:6311-6317. https://doi.org/10.3168/jds.2019-18116.

Pryce, J. E., R. Woolaston, D. P. Berry, E. Wall, M. Winters, R. Butler, and M. Shaffer. 2014. World trends in dairy cow fertility. Abstract 154 in 10th World Congress on Genetic Applied to Livestock Production. American Society of Animal Science.

Sarakul, M., M. A. Elzo, S. Koonawootrittriron, T. Suwanasopee, and D. Jattawa. 2018. Genetic parameters, predictions, and rankings for semen production traits in a Thailand multi-breed dairy population using genomic-polygenic and polygenic models. Anim. Reprod. Sci. 195:71-79. https://doi.org/10.1016/j.anireprosci.2018 .05 .008 .

\section{ORCIDS}

H. B. Olsen (ㄴ) https://orcid.org/0000-0002-0831-793X

B. Heringstad ๑ https://orcid.org/0000-0001-7388-3893

G. Klemetsdal @ https://orcid.org/0000-0002-4676-9005 